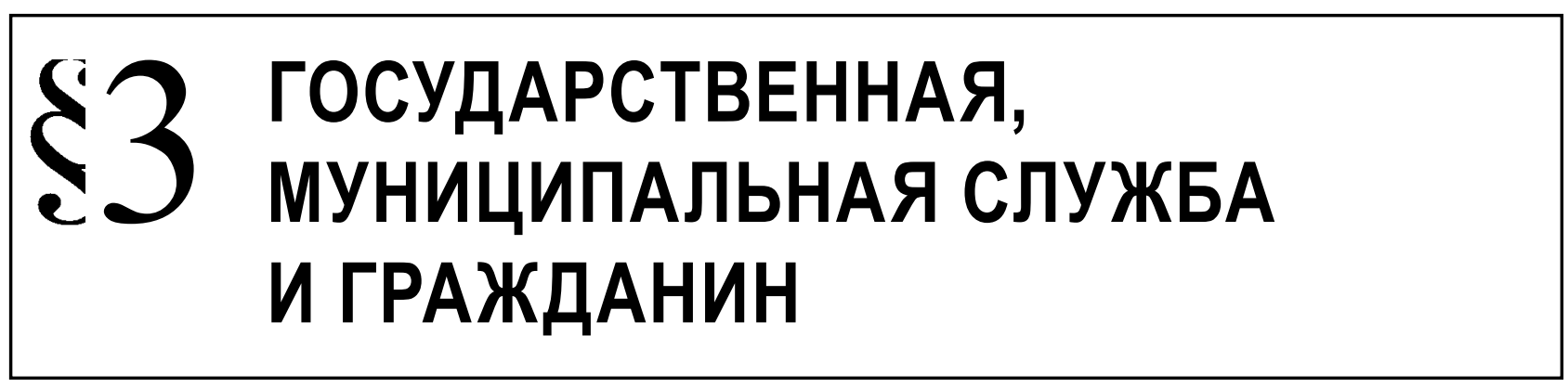

Полевец И.М.

\title{
СООТНОШЕНИЕ ВОЕННОЙ СЛУЖБЫ С ИНЫМИ ВИДАМИ ФЕДЕРАЛЬНОЙ ГОСУДАРСТВЕННОЙ СЛУЖБЫ
}

Аннотация. Предметом исследования являлись существующие виды государственной службы в Российской Федерации, установление основных принципов построения и функционирования системы государственной службы, предназначения этих видов государственной службы. Дать определения, существующих видов государственной службы и установить признаки, характерные непосредственно для военной службы. Рассмотреть существуюшую систему правового регулирования видов государственной службы. Произвести сопоставление систем социальных гарантий отдельных видов государственной службы. Установить единые подходы для военной и правоохранительной службы, с учетом условий прохождения этих видов государственной службы. Сравнительный анализ норм действующего законодательства о государственной службе, способствующий выявлению общих принципов построения государственной службы. и соотношения отдельных видов службы. В результате исследования установлена, взаимосвязь военной службы с иными видами федеральной государственной службы. Это обеспечивается на основе единства всей системы государственной службы в Российской Федерации, а также единых подходов к принципам построения и функционирования системы государственной службы в Российской Федерации.Установлено, что до настоящего времени федеральный закон о правоохранительной службе не принят, что создает правовую неопределенность в определении органов государственной власти осуществляющих правоохранительные функции.

Ключевые слова: виды, военная служба, отличительные особенности, правовое регулирование, принципы, вооруженные силы, правоохранительная, служба, взаимосвязь, отношение.

Review: The subject of the research covers the existing forms of public service in the Russian Federation, the basic principles of the system of public service creation and functioning, the role of these forms of public service. The author attempts to define the existing forms of public service and to define its features. The aim of the author is to consider the existing system of legal regulation of the forms of public service; to compare the social safeguards of particular forms of public service; to establish common approaches to military and law-enforcement service taking into account the conditions of service. The author carries out the comparative analysis of the existing legal regulations on public service and particular forms of service. The author reveals the interdependence of military service and other forms of federal public service. It is based on the unity of the whole system of public service in the Russian Federation and common approaches to the principles of creation and functioning of the system of public service in the Russian Federation. The author states that the federal law on law-enforcement service still hasn't been adopted; it causes legal ambiguity in definition of the bodies of public authority, exercising law-enforcement functions.

Keywords: forms, military service, features, legal regulation, principles, armed forces, law-enforcement, service, interdependence, correlation.

$\prod$ равовое регулирование и организация федеральной государственной службы находятся в ведении Российской Федерации, что прямо установлено статьей 71 Конституции Российской Федерации.
Система государственной службы в Российской Федерации сформирована в соответствии с Федеральным законом от 27 мая 2003 г. № 58-Ф3 «0 системе государственной службы Российской Федерации» (далее - Федеральный закон) [1]. 
Государственная служба Российской Федерации - профессиональная служебная деятельность граждан Российской Федерации по обеспечению исполнения полномочий: Российской Федерации; федеральных органов государственной власти, иных федеральных государственных органов; субъектов Российской Федерации; органов государственной власти субъектов Российской Федерации, иных государственных органов субъектов Российской Федерации; лиц, замещающих должности, устанавливаемые Конституцией Российской Федерации, федеральными законами для непосредственного исполнения полномочий федеральных государственных органов; лиц, замещающих должности, устанавливаемые конституциями, уставами, законами субъектов Российской Федерации для непосредственного исполнения полномочий государственных органов субъектов Российской Федерации.

Ранее в Российской Федерации действовал Федеральный закон от 31 июля 1995 г. № 119-ФЗ «Об основах государственной службы Российской Федерации» [2].

Статья 2 вышеуказанного Федерального закона, определяла под государственной службой профессиональную деятельность по обеспечению исполнения полномочий государственных органов.

Система государственной службы включает в себя следующие виды государственной службы: государственная гражданская служба; военная служба; правоохранительная служба.

Государственная гражданская служба подразделяется на федеральную государственную гражданскую службу и государственную гражданскую службу субъекта Российской Федерации.

Военная служба и правоохранительная служба являются видами федеральной государственной службы.

Статья 4 Федерального закона устанавливает, что федеральная государственная служба - профессиональная служебная деятельность граждан по обеспечению исполнения полномочий Российской Федерации, а также полномочий федеральных государственных органов и лиц, замещающих государственные должности Российской Федерации.

Предметом рассмотрения в настоящей статье будут отличия военной службы от федеральной государственной гражданской службы, а также правоохранительной службы.

Статья 6 Федерального закона предусматривает, что военная служба - вид федеральной государственной службы, представляющей собой профессиональ- ную служебную деятельность граждан на воинских должностях или не на воинских должностях в случаях и на условиях, предусмотренных федеральными законами и (или) нормативными правовыми актами Президента Российской Федерации, в Вооруженных Силах Российской Федерации, других войсках, воинских (специальных) формированиях и органах, осуществляющих функции по обеспечению обороны и безопасности государства. Таким гражданам присваиваются воинские звания.

В свою очередь законодательством, в статье 2 Федерального закона от 28 марта 1998 г. №53-Ф3 «0 воинской обязанности и военной службе» (далее Закон о военной службе), дается определение «военной службы» и указывается на ее особый вид [3].

Согласно Федеральному закону субъектами государственной службы могут быть только граждане Российской Федерации, а по Закону о военной службе - как граждане, не имеющие иностранного гражданства или подданства, так и граждане, имеющие гражданство (подданство) иностранного государства, и иностранные граждане.

Учитывая изложенное, необходимо выделить характерные признаки, которые придают военной службе особый вид, а также установить взаимную связь между военной службой и иными видами федеральной государственной службы.

Согласно толковому словарю Ушакова Д.Н., соотношение - это взаимное отношение, связь между двумя или несколькими предметами или явлениями [4].

По мнению автора, к числу данных признаков следует отнести следующие особенности, являющиеся свойственными для военной службы.

Статья 6 Федерального закона от 27 июля 2004 г. № 79-Ф3 «0 государственной гражданской службе Российской Федерации» устанавливает взаимосвязь гражданской службы и государственной службы Российской Федерации иных видов [5].

Указанная взаимосвязь обеспечивается на основе единства системы государственной службы Российской Федерации и принципов ее построения и функционирования, а также посредством:

- соотносительности основных условий и размеров оплаты труда, основных государственных социальных гарантий;

- установления ограничений и обязательств при прохождении государственной службы Российской Федерации различных видов;

- учета стажа государственной службы Российской Федерации иных видов при исчислении стажа гражданской службы; 
- соотносительности основных условий государственного пенсионного обеспечения граждан, проходивших государственную службу Российской Федерации.

Данные направления, обеспечивающие взаимосвязь гражданской службы и государственной службы Российской Федерации иных видов будут рассмотрены ниже.

Принцип единства системы государственной службы, установленный Федеральным Законом, предусматривает наличие единых подходов к организации государственной службы.

Федеральные законы о видах государственной службы обеспечивают реализацию принципов построения и функционирования системы государственной службы.

Указанными федеральными законами могут быть предусмотрены также другие принципы построения и функционирования видов государственной службы, учитывающие их особенности.

Статья 3 Федерального закона к основным принципам построения и функционирования системы государственной службы относит:

- федерализм, обеспечивающий единство системы государственной службы и соблюдение конституционного разграничения предметов ведения и полномочий между федеральными органами государственной власти и органами государственной власти субъектов Российской Федерации (далее - государственные органы);

- законность;

- $\quad$ приоритет прав и свобод человека и гражданина, их непосредственное действие, обязательность их признания, соблюдения и защиты;

- равный доступ граждан к государственной службе;

- единство правовых и организационных основ государственной службы, предполагающее законодательное закрепление единого подхода к организации государственной службы;

- взаимосвязь государственной службы и муниципальной службы;

- открытость государственной службы и ее доступность общественному контролю, объективное информирование общества о деятельности государственных служащих;

- профессионализм и компетентность государственных служащих;

- защита государственных служащих от неправомерного вмешательства в их профессиональную служебную деятельность как госу- дарственных органов и должностных лиц, так и физических и юридических лиц.

Правовое регулирование военной службы осуществляет Федеральный закон «О воинской обязанности и военной службе», а правовое регулирование федеральной государственной гражданской службы осуществляет Федеральный закон «0 государственной гражданской службе Российской Федерации».

Правовое регулирование правоохранительной службы осуществляют следующие федеральные законы:

- Федеральный закон от 3 апреля 1995 г. № 40Ф3 «0 Федеральной службе безопасности» [6];

- Федеральный закон от 21 июля 1997 г. № 118Ф3 «0 судебных приставах» [7];

- Федеральный закон от 7 февраля 2011 г. № 3-ФЗ «О полиции» [8];

- $\quad$ Федеральный закон от 21 июля 1997 г. № 114Ф3 «0 службе в таможенных органах Российской Федерации» [9];

- Федеральный закон от 30 ноября 2011 г. № 342-Ф3 «0 службе в органах внутренних дел Российской Федерации и внесении изменений в отдельные законодательные акты Российской Федерации» [10];

- Федеральный закон от 17 января 1992 г. № 2202-1 «0 прокуратуре Российской Федерации» [11];

- Федеральный закон от 28.12.2010 N 403-Ф3 «0 Следственном комитете Российской Федерации» [12].

- Федеральный закон «О системе государственной службы Российской Федерации» впервые дал определение правоохранительной службы. Правоохранительная служба - вид федеральной государственной службы, представляющей собой профессиональную служебную деятельность граждан на должностях правоохранительной службы в государственных органах, службах и учреждениях, осуществляющих функции по обеспечению безопасности, законности и правопорядка, по борьбе с преступностью, по защите прав и свобод человека и гражданина. Таким гражданам присваиваются специальные звания и классные чины.

Статья 19 Федерального закона устанавливает, что определение правоохранительной службы применяется со дня вступления в силу федерального закона о правоохранительной службе.

До настоящего времени федеральный закон о правоохранительной службе не принят, что, по мнению автора, создает правовую неопределен- 
ность в определении органов государственной власти осуществляющих правоохранительные функции.

Наиболее общее отличие правоохранительной и военной видов государственной службы от гражданской государственной службы заключается в предназначении этих видов государственной службы, т.е. в выполняемых ими функциях и задачах [13].

Для военной службы характерны следующие признаки:

- специфика выполняемых задач и функций в области обороны и военной безопасности;

ции военной службы;

- особые условия службы, нередко сопряженные с риском для жизни и здоровья;

- особые служебные обязанности (обязанности военной службы);

- наличие регулирования военно-служебных отношений через общевоинские уставы Вооруженных Сил Российской Федерации, в том числе Дисциплинарный Устав Вооруженных Сил Российской Федерации, учитывающие особенности должностных функций и условия военной службы;

- особые условия и порядок поступления на военную службу, ее прохождения, присвоения воинских званий, назначения на должности, прекращения службы;

- наличие особого статуса военнослужащих;

- особый порядок привлечения к видам правовой ответственности (прежде всего уголовной, дисциплинарной и материальной);

- специальное обеспечение (денежное довольствие, социальные гарантии, форма, знаки различия и отличия и т.п.).

Как видно, многие из перечисленных отличительных признаков имеют особый характер.

Функциональное предназначение отдельных видов государственной службы обусловливает их специфику и отличия военной службы от других видов государственной службы Российской Федерации.

Военная служба имеется ряд существенных различий, по отношению к другим видам государственной службы.

К числу отличительных функций военной службы от правоохранительной службы следует отнести функции по обеспечению обороны и безопасности государства.

Функции по обеспечению безопасности, законности и правопорядка, по борьбе с преступностью, по защите прав и свобод человека и гражданина отнесены к правоохранительной службе.

В соответствии с Федеральным законом от 31 мая 1996г. № 61-Ф3 «Об обороне» (далее - Закон об обороне) под обороной понимается система политических, экономических, военных, социальных, правовых и иных мер по подготовке к вооруженной защите и вооруженная защита Российской Федерации, целостности и неприкосновенности ее территории [14].

В целях обороны создаются Вооруженные Силы Российской Федерации, к обороне привлекаются внутренние войска Министерства внутренних дел Российской Федерации.

В соответствии со статьей 10 Закона об обороне Вооруженные Силы Российской Федерации - государственная военная организация, составляющая основу обороны Российской Федерации.

Вооруженные Силы Российской Федерации предназначены для отражения агрессии, направленной против Российской Федерации, для вооруженной защиты целостности и неприкосновенности территории Российской Федерации, а также для выполнения задач в соответствии с федеральными конституционными законами, федеральными законами и международными договорами Российской Федерации.

В целях защиты интересов Российской Федерации и ее граждан, поддержания международного мира и безопасности формирования Вооруженных Сил Российской Федерации могут оперативно использоваться за пределами территории Российской Федерации в соответствии с общепризнанными принципами и нормами международного права, международными договорами Российской Федерации и настоящим Федеральным законом для решения ряда задач (отражение вооруженного нападения на формирования Вооруженных Сил Российской Федерации, другие войска или органы, дислоцированные за пределами территории Российской Федерации; отражение или предотвращение вооруженного нападения на другое государство, обратившееся к Российской Федерации с соответствующей просьбой; защита граждан Российской Федерации за пределами территории Российской Федерации от вооруженного нападения на них; борьба с пиратством и обеспечение безопасности судоходства).

Таким образом, военная служба направлена на обеспечение обороны и безопасности государства, правоохранительная служба обеспечивает безопасность внутри государства, законность и право- 
порядок, а также борьбу с преступностью и защиту прав и свобод человека и гражданина.

В соответствии с Федеральным законом государственная гражданская служба - вид государственной службы, представляющей собой профессиональную служебную деятельность граждан на должностях государственной гражданской службы по обеспечению исполнения полномочий федеральных государственных органов, государственных органов субъектов Российской Федерации, лиц, замещающих государственные должности Российской Федерации, и лиц, замещающих государственные должности субъектов Российской Федерации.

Федеральная государственная гражданская служба - профессиональная служебная деятельность граждан на должностях федеральной государственной гражданской службы по обеспечению исполнения полномочий федеральных государственных органов и лиц, замещающих государственные должности Российской Федерации.

Так, например, система федеральных органов исполнительной власти установлена Указом Президента Российской Федерации от 9 марта 2004 г. № 314 «0 системе и структуре федеральных органов исполнительной власти» [15].

В настоящее время структура федеральных органов исполнительной власти установлена Указом Президента Российской Федерации от 21 мая 2012 г. № 636 «0 структуре федеральных органов исполнительной власти» [16].

Полномочия федеральных органов исполнительной власти определены в соответствующем положении, утверждаемом указом Президента Российской Федерации или постановлением Правительства Российской Федерации, в зависимости от того, кем осуществляется руководство деятельностью того или иного органа исполнительной власти.

Положения о федеральном органе исполнительной власти содержит функции и задачи федерального органа исполнительной власти, его полномочия, а также организацию деятельности данного органа.

Согласно словарю Ушакова одно из значений слова «функция» - обязанность, круг деятельности, подлежащая исполнению работа; «задача» - цель, то, что необходимо осуществить, чего необходимо достигнуть; «полномочия» - власть или право, предоставленные кому-нибудь [17].

Отдельно хотелось бы отметить, что полномочия федерального органа исполнительной власти могут осуществляться путем прохождения в нем как военной службы, так и федеральной государственной гражданской службы.

Возвращаясь к четырем направлениям, обеспечивающим взаимосвязь гражданской службы и государственной службы Российской Федерации иных видов, необходимо отметить следующее [18].

Указом Президента РФ от 1 февраля 2005 г. № 113 «0 порядке присвоения и сохранения классных чинов государственной гражданской службы Российской Федерации федеральным государственным гражданским служащим» утверждена таблица соотношения классных чинов федеральной государственной гражданской службы, воинских и специальных званий, классных чинов юстиции, классных чинов прокурорских работников [19].

Пункт 22 Положения о порядке присвоения и сохранения классных чинов государственной гражданской службы Российской Федерации федеральным государственным гражданским служащим, утвержденного Указом Президента Российской Федерации от 1 февраля 2005 г. № 113 предусматривает, следующую особенность для присвоения классного чина, так если в соответствии с таблицей соотношения классных чинов федеральной государственной гражданской службы, воинских и специальных званий, классных чинов юстиции, классных чинов прокурорских работников первый классный чин гражданской службы, который должен быть присвоен федеральному гражданскому служащему в соответствии с пунктом 6 Положения, ниже имеющегося у федерального гражданского служащего воинского или специального звания, классного чина юстиции, классного чина прокурорского работника, то федеральному гражданскому служащему присваивается классный чин гражданской службы на одну ступень выше того классного чина, который должен быть ему присвоен в соответствии с пунктом 6 Положения.

Присвоенный классный чин сохраняется за федеральным гражданским служащим при освобождении от замещаемой должности гражданской службы и увольнении с гражданской службы (в том числе в связи с выходом на пенсию), а также при поступлении на гражданскую службу вновь.

Отдельно следует отметить, что в случае поступления гражданина на военную службу, классный чин государственной гражданской службы Российской Федерации не учитывается при присвоении воинского звания.

Следует отметить, что для служащих правоохранительных органов, военнослужащих и гражданских служащих установлены единые ограничения 
и запреты, связанные с противодействием коррупции на государственной службе, и аналогичная система ответственности за их несоблюдение.

Данные запреты установлены статьями 17, 18 и 20 Федерального закона от 27 июля 2004 г. № 79-Ф3 «0 государственной гражданской службе Российской Федерации», а также Федеральным законом от 25 декабря 2008 г. № 273-ФЗ «0 противодействии коррупции» [20].

Ограничения, запреты и обязанности, связанные со службой в полиции и прохождением военной службы, установлены статьей 29 Федерального закона от 7 февраля 2011 г. № 3-Ф3 «0 полиции» и статьей 27.1 Федерального закона от 27 мая 1998 года № 76-Ф3 «О статусе военнослужащих» [21].

Указанные нормы носят отсылочный характер, к Федеральному закону от 25 декабря 2008 г. № 273-Ф3 «0 противодействии коррупции», а также к статьям 17, 18 и 20 Федерального закона от 27 июля 2004 г. № 79-Ф3 «0 государственной гражданской службе Российской Федерации».

Сопоставление систем социальных гарантий отдельных видов государственной службы демонстрирует единые подходы для военной и правоохранительной службы, что объясняется схожими условиями прохождения этих видов государственной службы.

Существенные отличия в объеме и характере социальных гарантий, предусмотренных для служащих, проходящих государственную службу различных видов, как правило, не имеют достаточного обоснования.

В соответствии со статьей 57 Закона Российской Федерации от 12 февраля 1993 г. № 4468-1 «0 пенсионном обеспечении лиц, проходивших военную службу, службу в органах внутренних дел, Государственной противопожарной службе, органах по контролю за оборотом наркотических средств и психотропных веществ, учреждениях и органах уголовно-исполнительной системы, и их семей» для военнослужащих и служащих правоохранительных органов предусмотрено сохранение выплаты пенсии за выслугу лет в случае продолжения их трудовой деятельности, в том числе на гражданской службе [22].

В то же время на гражданских служащих, имеющих пенсию за выслугу лет и продолжающих свою трудовую деятельность, такая гарантия не распространяется, следовательно, выплата пенсии за выслугу лет при выходе на работу приостанавливается.

Согласно пункту 3 статьи 7 Федерального закона от 15 декабря 2001 г. № 166-Ф3 «0 государ- ственном пенсионном обеспечении в Российской Федерации» пенсия за выслугу лет не выплачивается в период прохождения государственной службы Российской Федерации, при замещении государственной должности Российской Федерации, государственной должности субъекта Российской Федерации, муниципальной должности, замещаемой на постоянной основе, должности муниципальной службы, а также в период работы в межгосударственных (межправительственных) органах, созданных с участием Российской Федерации, на должностях, по которым в соответствии с международными договорами Российской Федерации осуществляются назначение и выплата пенсий за выслугу лет в порядке и на условиях, которые установлены для федеральных государственных (гражданских) служащих [23].

При последующем увольнении с государственной службы Российской Федерации или освобождении от указанных должностей выплата пенсии за выслугу лет возобновляется со дня, следующего за днем увольнения с указанной службы или освобождения от указанных должностей гражданина, обратившегося с заявлением о ее возобновлении.

Введенное Указом Президента Российской Федерации от 7 июня 2011 г. № 720 соотношение классных чинов федеральной государственной гражданской службы, воинских и специальных званий, классных чинов юстиции учитывается только при поступлении государственного служащего, имеющего воинское и специальное звание или классный чин юстиции, на гражданскую службу [24].

При переходе гражданского служащего на военную службу или на работу в правоохранительный орган его классный чин гражданской службы при присвоении воинских и специальных званий не учитывается.

В соответствии со статьей 54 Федерального закона в стаж (общую продолжительность) гражданской службы для установления ежемесячной надбавки к должностному окладу за выслугу лет, определения продолжительности ежегодного дополнительного оплачиваемого отпуска за выслугу лет и размера поощрений за безупречную и эффективную гражданскую службу включаются периоды замещения должностей гражданской службы, воинских должностей и должностей правоохранительной службы. Аналогичный подход применяется при исчислении стажа военной службы и правоохранительной службы, в который, как правило, стаж гражданской службы не засчитывается. 
Административное и муниципальное право 6 (90) 2015

Что касается соотносительности размеров оплаты труда, следует отметить следующее.

Указом Президента Российской Федерации от 2 августа 2012 г. № 1100 «0 совершенствовании оплаты труда федеральных государственных гражданских служащих Администрации Президента Российской Федерации» утверждены таблица соотношения должностей федеральной государственной гражданской службы в Администрации Президента Российской Федерации и воинских должностей военнослужащих, проходящих военную службу по контракту, а также таблица соотношения классных чинов федеральной государственной гражданской службы и воинских званий [25].

Пунктом 5 данного Указа предусмотрено, что при повышении (индексации) окладов по воинским должностям военнослужащих, проходящих военную службу по контракту, и окладов по воинским званиям военнослужащих одновременно и в таком же размере повышаются (индексируются) месячные оклады федеральных государственных гражданских служащих.
Таким образом, взаимосвязь военной службы с иными видами федеральной государственной службы обеспечивается на основе единства всей системы государственной службы в Российской Федерации, а также единых подходов к принципам построения и функционирования.

По мнению автора, на протяжении последних нескольких лет соотношение военной службы с иными видами федеральной государственной службы, в части соотносительности основных условий и размеров оплаты труда, основных государственных социальных гарантий; установления ограничений и обязательств при прохождении государственной службы Российской Федерации различных видов; учета стажа государственной службы Российской Федерации иных видов при исчислении стажа гражданской службы; соотносительности основных условий государственного пенсионного обеспечения граждан, проходивших государственную службу Российской Федерации, неуклонно стремится к минимуму, что существенно отражается на особом виде военной службы.

\section{Библиография:}

1. СЗ РФ, 02.06.2003, № 22, ст. 2063.

2. СЗ РФ, 31.07.1995, № 31, ст. 2990.

3. СЗ РФ, 30.03.1998 г., № 13, ст. 1475.

4. Толковый словарь русского языка под редакцией Д.Н.Ушакова.

5. Российская газета, № 162, 31.07.2004 г.

6. СЗ РФ, 10.04.1995 г., № 15, ст. 1269.

7. С Р РФ, 28.07.1997 г., № 30, ст. 3590.

8. Российская газета, № 25, 08.02.2011 г.

9. СЗ РФ, 28.07.1997 г., № 30, ст. 3586.

10. СЗ РФ, 05.12.2011 г., № 49 (ч. 1), ст. 7020.

11. СЗ РФ, 20.11.1995 г., № 47, ст. 4472.

12. Российская газета, № 296, 30.12.2010 г.

13. См.: В.М. Корякин, А.В. Кудашкин, К.В. Фатеев. Военно-административное право (военная администрация). М.: «За права военнослужащих», 2008. С. 195.

14. СЗ РФ, 03.06.1996 г., № 23, ст. 2750.

15. Российская газета, № 50, 12.03 .2004 .

16. Российская газета, № $114,22.05 .2012$.

17. Толковый словарь русского языка под редакцией Д.Н.Ушакова.

18. См.: «Комментарий к Федеральному закону от 27 июля 2004 г. № 79-Ф3 «О государственной гражданской службе Российской Федерации» (постатейный) (2-е издание, переработанное и дополненное) Нечаева Т.В., Кирилин А.В., «Деловой двор», 2013.

19. Российская газета, № 20, 03.02.2005 г.

20. СЗ РФ, 29.12.2008, № 52 (ч. 1), ст. 6228.

21. СЗ РФ, 01.06.1998,№ 22 ст. 2331.

22. Ведомости СНД РФ и ВС РФ, 04.03.1993, № 9, ст. 328.

23. СЗ РФ, 17.12.2001 г., № 51, ст. 4831.

24. СЗ РФ, 13.06.2011 г., № 24, ст. 3408.

25. СЗ РФ, 06.08.2012 г., № 32, ст. 4490.

\section{References (transliterated):}

1. SZ RF, 02.06.2003, № 22, st. 2063. 
2. SZ RF, 31.07.1995, № 31, st. 2990.

3. SZ RF, 30.03.1998 g., № 13, st. 1475.

4. Tolkovyi slovar' russkogo yazyka pod redaktsiei D.N.Ushakova.

5. Rossiiskaya gazeta, № 162, 31.07.2004 g.

6. SZ RF, 10.04.1995 g., № 15, st. 1269.

7. SZ RF, 28.07.1997 g., № 30, st. 3590.

8. Rossiiskaya gazeta, № $25,08.02 .2011 \mathrm{~g}$.

9. SZ RF, 28.07.1997 g., № 30, st. 3586.

10. SZ RF, 05.12.2011 g., № 49 (ch. 1), st. 7020.

11. SZ RF, 20.11.1995 g., № 47, st. 4472.

12. Rossiiskaya gazeta, № 296, 30.12.2010 g.

13. Sm.: V.M. Koryakin, A.V. Kudashkin, K.V. Fateev. Voenno-administrativnoe pravo (voennaya administratsiya). M.: «Za prava voennosluzhashchikh», 2008. S. 195.

14. SZ RF, 03.06.1996 g., № 23, st. 2750.

15. Rossiiskaya gazeta, № 50, 12.03.2004.

16. Rossiiskaya gazeta, № $114,22.05 .2012$.

17. Tolkovyi slovar' russkogo yazyka pod redaktsiei D.N.Ushakova.

18. Sm.: «Kommentarii k Federal'nomu zakonu ot 27 iyulya 2004 g. № 79-FZ «O gosudarstvennoi grazhdanskoi sluzhbe Rossiiskoi Federatsii» (postateinyi) (2-e izdanie, pererabotannoe i dopolnennoe) Nechaeva T.V., Kirilin A.V., «Delovoi dvor», 2013.

19. Rossiiskaya gazeta, № 20,03.02.2005 g.

20. SZ RF, 29.12.2008, № 52 (ch. 1), st. 6228.

21. SZ RF, 01.06.1998,№ 22 st. 2331.

22. Vedomosti SND RF i VS RF, 04.03.1993, № 9, st. 328.

23. SZ RF, 17.12.2001 g., № 51 , st. 4831.

24. SZ RF, 13.06.2011 g., № 24, st. 3408.

25. SZ RF, 06.08.2012 g., № 32, st. 4490. 